\title{
Associations of alcohol consumption with chronic diseases, lifestyle behaviors and socioeconomic-demographic characteristics in India
}

\author{
Sunita Patel ${ }^{1}$, Faujdar Ram ${ }^{1,2}$, Charles Parry ${ }^{3,4}$, and Surendra Kumar Patel ${ }^{1}$ \\ ${ }^{1}$ International Institute for Population Sciences (IIPS), Mumbai, Maharashtra, India \\ ${ }^{2}$ Population Council, New Delhi, India \\ ${ }^{3}$ Alcohol, Tobacco and Other Drug Research Unit, South African Medical Research Council, Cape Town, South Africa \\ ${ }^{4}$ Department of Psychiatry, Stellenbosch University, Cape Town, South Africa
}

\begin{abstract}
Aims: The objective of the present study was to analyse self-reported and measured chronic diseases and their association with alcohol consumption. Furthermore, the study examined the intensity and patterns of alcohol consumption by lifestyle and sociodemographic characteristics among respondents with chronic diseases.

Methods: Secondary data were analysed from the Study on Global AGEing and Adult Health (SAGE), Wave 1 (2007-08), covering respondents aged 18 and older $(10,914)$ in India. Chronic diseases, namely chronic obstructive pulmonary disease (COPD), hypertension, asthma, depression and angina were self-reported as diagnoses and measured using validated epidemiological tools. A multivariable adjusted logistic regression model was used to analyze the association of quantity of alcohol consumed and patterns of alcohol consumption with chronic diseases. A multinomial multivariable regression model was used to examine the risk ratio between alcohol consumption and each lifestyle characteristic among the diseased population.
\end{abstract}

Results: About $17.0 \%(1,432 / 10,914)$ of the population consumed alcohol. At $18.0 \%(1,967 / 10,914)$, the prevalence of selfreported chronic diseases was lower than measured chronic diseases $(37.5 \%$; 4091/10,914). Moderate drinking was associated with self-reported hypertension $(\mathrm{OR}=1.68 ; 95 \% \mathrm{CI}=1.10,2.55)$ and measured hypertension $(\mathrm{OR}=1.67 ; 95 \% \mathrm{CI}=1.16,2.42)$. Consumption of three or more alcoholic drinks per session was associated with self-reported depression $(\mathrm{OR}=2.68 ; 95 \% \mathrm{CI}=$ $1.32,5.45)$. Alcohol consumption of more than three drinks per session was associated with vigorous physical activity $(\mathrm{RRR}=$ $3.57 ; 95 \% \mathrm{CI}=1.25,10.23$ ). Heavy drinking was associated with the risk of having a body mass index in the overweight range $(\mathrm{RRR}=2.29 ; 95 \% \mathrm{CI}=1.17,4.47)$.

Conclusions: The study findings demonstrate that alcohol is a risk factor for hypertension, self-reported depression and being overweight, with these associations varying with the amount of alcohol consumed. A coordinated, targeted multisectoral approach is needed to improve knowledge and awareness of the harmful effects of alcohol consumption and to strengthen alcohol use control policies in India.

\section{Introduction}

Globally, non-communicable diseases (NCDs) are a leading cause of mortality, accounting for 39.5 million deaths per year (Naghavi et al., 2017). A majority of the deaths are attributed to cardiovascular diseases (17.5 million), diabetes (14.4 million), neoplasm (8.3 million), chronic obstructive pulmonary disease (COPD; 2.9 million), and asthma (0.4 million) (Naghavi et al., 2017). The World Health Organization (WHO) in 2004 reported that, worldwide, 35 million deaths and 603 million Disability Adjusted Life Years (DALYs) were caused by chronic diseases and their conditions (WHO, 2008). Low- and middle-income countries experienced the bulk $(82 \%)$ of premature $(\leq 70$ years) deaths (WHO, 2014). In India, NCDs contributed to $61.8 \%$ of all causes of deaths in 2016 (Dandona et al., 2017). Furthermore, in 2016, cardiovascular diseases alone accounted for $28.1 \%$ of deaths and chronic respiratory diseases accounted for $10.9 \%$ of total deaths in India (Prabhakaran et al., 2018). In 2012, alcohol alone caused 3.3 million $(5.9 \%)$ deaths and $5.1 \%$ of DALYs across the world (WHO, 2014). The WHO reported that the per capita consumption of pure alcohol was 6.4 liters worldwide and 5.7 liters in India among the population aged 15 and older, and that alcohol alone was responsible for $7.2 \%$ of premature

Correspondence: Sunita Patel, International Institute for Population Sciences, Mumbai, Maharashtra, India

Email: sunitapatel56@iips.net

Financial support: No financial support was provided for this study.

Declaration of interest: None

Keywords: alcohol, self-reported chronic diseases, measured chronic diseases, lifestyle behaviors, quantity and pattern of drinking 
mortality worldwide in 2016 ( $\leq 69$ years) (WHO, 2018). Alcohol consumption and raised blood pressure are among the top five risk factors for NCDs (WHO, 2014).

Alcohol consumption adversely affects human health, causing many chronic diseases such as hypertension (Ji et al., 2018; Roerecke et al., 2017), ischemic heart disease (Larsson, Wallin, \& Wolk, 2018; Mahajan et al., 2018), COPD (Patel, Ram, Patel, \& Kumar, 2019), cancers, hemorrhagic stroke, and liver disease (Parry, Patra, \& Rehm, 2011; Rehm et al., 2013). Several studies have suggested that alcohol has both beneficial and detrimental effects on human health depending on the quantity of alcohol consumed (Larsson et al., 2018; Rehm et al., 2010; Santana et al., 2018; Shield, Parry, \& Rehm, 2013). Consumption of alcohol has been found to be significantly associated with high blood pressure among men with moderate drinking (1-209 g/ethanol/week) and heavy drinking ( $\geq 210 \mathrm{~g} /$ ethanol/week) and among women with heavy drinking $(\geq 140$ g/ethanol/week) (Santana et al., 2018). A significant association has been found between the intake of alcohol and asthma among adults (12-41 years) (Lieberoth et al., 2012). Furthermore, this research has shown that there is a low risk of asthma in moderate weekly drinkers (1-6 units/week), and a high risk among light/never drinkers ( $<1$ unit/month), and heavy drinkers ( $\geq 4$ units/day) (U-shaped relationship) (Lieberoth et al., 2012). Therefore, different studies have demonstrated that the quantity of alcohol consumption is an important factor in the development and worsening of chronic diseases.

Many studies have demonstrated the adverse effects of alcohol consumption on health vis-à-vis chronic diseases. Light and moderate alcohol intake have been found to be associated with reduced mortality from cardiovascular diseases (CVDs) (Xu et al., 2007). Low alcohol intake was not found to be associated with hypertension among men, while it conferred a small protective effect on women (Ridolfo \& Stevenson, 2001). WHO (2018) estimated that the per-capita alcohol consumption in the population aged 15 and older increased from $2.7 \mathrm{~L}$ to $3.0 \mathrm{~L}$ between 2010 and 2016 in India. About $38.6 \%$ and $7.3 \%$ of the population of India were respectively current drinkers and heavy drinkers; the highest prevalence of current drinkers (40.6\%) was in the age group of 30-49 years, whereas that of heavy drinkers $(24.7 \%)$ was in the age group of 50 years and older (Kumar, Kumar, \& Singh, 2018). Research has found that quantity and patterns of drinking have a complex association with chronic diseases, making alcohol an important public health concern (Lachenmeier \& Rehm, 2009; Shield et al., 2013). The United Nations Sustainable Development Goal (3.4 \& 3.5 ) is focused on prevention of harmful use of alcohol and a reduction by one third in premature mortality from NCDs by 2030 (Bhamra et al., 2015). Therefore, better information on the estimated quantity of alcohol consumption at a country level is needed for understanding the risk factors of chronic diseases (Shield et al., 2013).

Several studies have focused on the association of alcohol with self-reported NCDs (Bhise \& Patra, 2018; Krishnan et al., 2008; Leong et al., 2014; Roy et al., 2010; Ruan et al., 2018; Venkataraman et al., 2013). However, only a handful of studies have focused on measured NCDs in India (Arokiasamy et al., 2017; Hoth et al., 2013; Patel et al., 2019; Vellakkal et al., 2013). There have been no studies that focus on alcohol measures (quantity and pattern) and their association with self-reported and measured chronic diseases in India. Previous research has suggested the need for research on the health consequences of alcohol with a focus on quantity and patterns of drinking (Gutjahr et al., 2001; Shield et al., 2013). However, a large proportion of the Indian population lacks awareness of chronic diseases and conditions (Arokiasamy et al., 2017; Vellakkal et al., 2013). Given this gap, the present study aimed to (1) analyze selfreported and measured chronic diseases and their association with the pattern and intensity of alcohol drinking, and (2) examine the intensity and patterns of alcohol drinking by lifestyle and socio-demographic characteristics among respondents with chronic diseases.

\section{Material and Methods}

The present study used data from the 2013 Study on Global AGEing and Adult Health (SAGE), Wave 1, which was carried out in India in 2007-08. The survey interviewed respondents aged 18 years and older from six states: Assam, Karnataka, Maharashtra, Rajasthan, Uttar Pradesh, and West Bengal. A total of 12,198 respondents were selected for the interviews, but the survey included only 11,230 participants because the others had either refused to participate or had moved elsewhere. Another 316 samples were excluded because their anthropometric measurements (weight and height) were missing. In all, only 10,914 samples were included in the analysis. The SAGE survey uses the multistage cluster sampling design. The Primary Sampling Units (PSUs) were drawn through probability proportional to size sampling. For the rural areas, a two-stage sampling was done, whereby villages were taken as the PSUs, and 25 households were interviewed from each selected village. A three-stage sampling design was used for the urban areas, such that city wards were selected as the PSUs first. Next, two census enumeration blocks were selected from each PSU. Finally, 33 households were selected from each census enumeration block for the interview. Overall, 285 villages and 93 census enumeration blocks were selected from each of the six states. The SAGE Wave 2 data are not available in the public domain; therefore, we used the Wave 1 (2007-08) data for this study (Arokiasamy, Parasuraman, Sekher, \& Lhungdim, 2013).

\section{Variables Used in the Analysis}

Five major diseases-hypertension, depression, asthma, COPD, and angina-were included as self-reported diagnoses and as measured using validated epidemiological tools for assessing chronic diseases. The survey asked two sets of questions of each respondent. The first set pertained to the self-reported chronic diseases and asked, with respect to angina: "Have you ever been diagnosed with angina or been told by a health professional that you have angina?" Similar questions were asked with regard to hypertension, depression, asthma, and COPD separately. In the second set, 
the respondents were asked questions on specific symptoms, measurement, and treatment related to the given diseases. The SAGE study used the WHO Rose Angina Questionnaire for the symptom-based assessment of angina pectoris (Arokiasamy et al., 2017). For asthma, the survey asked the respondents, "Have you experienced wheezing, whistling, feeling of tightness in your chest, or attack of shortness of breath during the last 12 months?" COPD was identified using a measurement test done with the help of a spirometer (Fishbacher, Bhopal, Unwin, White, \& Alberti, 2001). The test takes into consideration age and actual height of respondents. For our analysis, we took into consideration measurements that were categorized as "very severe." To measure depression, symptom-based questions were asked of each respondent (Kessler \& Ustun, 2004). For the assessment of hypertension, three sitting blood pressure readings were taken at one-minute intervals for each respondent. Respondents were categorized as hypertensive if their average systolic blood pressure exceeded $140 \mathrm{mmHg}$ and the diastolic blood pressure exceeded $90 \mathrm{mmHg}$.

To measure alcohol consumption, the survey asked the respondents if they had ever, or in the last 12 months, consumed alcohol such as beer, wine, spirits, etc. To measure the quantity of alcohol consumed, respondents were asked: "In the last 12 months, on the days you drank alcoholic beverages, how many drinks did you have on an average?" To measure the drinking pattern, the survey asked: "In the last 12 months, how frequently (how many days) on average have you had at least one alcoholic drink?"

The lifestyle characteristics included in the survey were physical activity, nutrition, tobacco, and body mass index. For physical activity, respondents were asked if they had done any vigorous activity (sport/fitness/recreational activity), moderate activity (carrying light loads, cleaning, moderate-intensity sports, etc.), or light physical activity/physical inactivity (used a bicycle/pedal cycle) for 10 minutes during the seven days preceding the survey. For nutritional intake, respondents were asked two questions related to the number of separate servings of fruits and vegetables they had on a typical day. For tobacco use, the respondents were asked if they had ever smoked tobacco/used any smokeless tobacco product on a daily basis. Body mass index was calculated by dividing body weight in kilograms by the square of the height in meters $\left(\mathrm{kg} / \mathrm{m}^{2}\right)$. Following the WHO guidelines, we categorized body mass index as underweight, normal weight, overweight, and obese (WHO, 2013).

The socioeconomic-demographic variables included were place of residence, sex, highest educational level, and age group. The wealth index was estimated based on the income of the respondents, and five categories were made: poorest, poor, middle, rich, and richest. Caste group and religion were also considered for the analysis.

\section{Statistical Analysis}

Descriptive statistics were used to estimate precentages and prevalence rates. The prevalence of chronic diseases was calculated as the rate of those having chronic diseases over the surveyed sample of the total study population. Prevalence rates of chronic diseases are based on weighted analysis. The prevalence was defined as the number of respondents suffering from at least one of the diseases, and it was calculated separately for self-reported and measured chronic diseases. Multivariable logistic regression models were fitted to assess the association of alcohol consumption with self-reported and measured chronic diseases, controlling for lifestyle behaviors as well as socioeconomicdemographic characteristics. The multinomial multivariable regression model of relative risk ratio (RRR) was used for estimating the risk of patterns and intensity of alcohol consumption for those who have self-reported and measured chronic diseases. For the multinomial model, the outcome variable used was the pattern of alcohol consumption among the diseased population (both self-reported and measured chronic diseases separately), where the base outcome was "do not drink." A similar method was followed for the intensity of alcohol consumption (Ahangari, Stewart Williams, \& Myleus, 2016). The RRR and odds ratio regression model presented effect estimates and 95\% confidence intervals (CIs). Population weights were applied to make the sample nationally representative. All the analysis was carried out using Stata 13 statistical software (Stata Corp, 2013).

\section{Results}

The profile of the respondents is presented in Table 1. As many as $69.1 \%$ of the respondents were from rural areas. About half of them $(51.7 \%)$ were males. Only $16.0 \%$ of the respondents had secondary education; $25.4 \%$ had primary education or less; $24.5 \%$ had high school and above education; and $34.2 \%$ had never gone to school. Nearly $49.5 \%$ of the respondents were from the 18-39 age group, $37.2 \%$ were from the $40-59$ age group, and the remaining respondents were aged 60 and older. About $20.3 \%$ of respondents were from the richest quintile and $20 \%$ each were from the poor and the poorest quintiles. Three quarters of respondents were from castes other than Scheduled Tribes (ST) and Scheduled Caste (SC). Nearly half of the respondents were vigorously $(51.1 \%)$ and $41.8 \%$ were moderately active, whereas only $7.1 \%$ were non-active. A majority of the respondents reported having an inadequate nutritional intake $(94.8 \%)$, and just under half were using tobacco products $(44.4 \%)$. Seventeen percent of the respondents reported consuming alcohol. 
Table 1

Respondents'demographic, socio-economic and life-style characteristics

\begin{tabular}{|c|c|c|}
\hline Socioeconomic-demographic characteristics & Percent & Sample $n$ \\
\hline \multicolumn{3}{|l|}{ Place of residence } \\
\hline Urban & 31.0 & 2,751 \\
\hline Rural & 69.1 & 8,163 \\
\hline \multicolumn{3}{|l|}{ Sex } \\
\hline Male & 51.7 & 4,249 \\
\hline Female & 48.3 & 6,665 \\
\hline \multicolumn{3}{|l|}{ Age group } \\
\hline $18-39$ & 49.5 & 3,160 \\
\hline $40-59$ & 37.2 & 4,273 \\
\hline 60 and above & 13.3 & 3,481 \\
\hline \multicolumn{3}{|l|}{ Highest education level } \\
\hline No education & 34.2 & 4,880 \\
\hline$\leq$ Primary & 25.4 & 2,834 \\
\hline Secondary & 16.0 & 1,353 \\
\hline High school and above & 24.5 & 1,847 \\
\hline \multicolumn{3}{|l|}{ Wealth Quintile } \\
\hline Poorest & 20.1 & 1,748 \\
\hline Poor & 20.5 & 2,035 \\
\hline Middle & 19.6 & 2,169 \\
\hline Rich & 19.5 & 2,490 \\
\hline Richest & 20.3 & 2,472 \\
\hline \multicolumn{3}{|l|}{ Religion } \\
\hline Hindu & 84.2 & 9,177 \\
\hline Others $^{+}$ & 15.9 & 1,737 \\
\hline \multicolumn{3}{|l|}{ Caste group } \\
\hline Scheduled Caste (SC)/Scheduled Tribes (ST) & 24.7 & 2,690 \\
\hline Other than SC/ST & 75.3 & 8,224 \\
\hline \multicolumn{3}{|l|}{ Physical activity } \\
\hline Non-active & 7.1 & 978 \\
\hline Moderately active & 41.8 & 5,437 \\
\hline Vigorously active & 51.1 & 4,499 \\
\hline \multicolumn{3}{|l|}{ Nutrition } \\
\hline Less than 5 servings of fruits and vegetables/day & 94.8 & 10,364 \\
\hline$\geq 5$ servings of fruits and vegetables/day & 5.2 & 550 \\
\hline \multicolumn{3}{|l|}{ Any tobacco use ${ }^{\wedge}$} \\
\hline No & 55.6 & 6,306 \\
\hline Yes & 44.4 & 4,608 \\
\hline \multicolumn{3}{|l|}{ Body Mass Index ${ }^{\wedge}$} \\
\hline Underweight & 52.9 & 3,795 \\
\hline Normal weight & 35.2 & 5,611 \\
\hline Overweight & 9.3 & 1,172 \\
\hline Obese & 2.6 & 336 \\
\hline \multicolumn{3}{|l|}{ Alcohol consumption } \\
\hline No & 83.0 & 9,482 \\
\hline Yes & 17.0 & 1,432 \\
\hline \multicolumn{3}{|l|}{ Pattern of alcohol consumption ${ }^{\#}$} \\
\hline No drinking & 83.0 & 9,482 \\
\hline Moderate drinking & 12.2 & 1,033 \\
\hline Heavy drinking & 4.7 & 399 \\
\hline \multicolumn{3}{|l|}{ Quantity of alcohol consumption } \\
\hline No drink & 83.0 & 9,482 \\
\hline At least two drinks & 12.9 & 1,147 \\
\hline$\geq 3$ drinks & 4.1 & 285 \\
\hline Total & 100 & 10,914 \\
\hline
\end{tabular}

Percentage distributions are based on weighted analysis while sample numbers $(n)$ are unweighted

+ Includes Islam, Buddhism, Christian, Jainism, Sikhism, and others

\# Alcohol consumption pattern was categorized as non-drinker, moderate drinker (1-3 days or fewer per month), and heavy drinker (1-4 and more days per week)

\#\# Quantity of alcohol consumption includes number of drinks per session

^Any tobacco includes ever or current users of smoke or smokeless tobacco products daily such as cigarettes, cigars, pipes, chewing tobacco, or snuff

${ }^{\wedge}$ Body mass index was categorized as underweight $\left(<18.5 \mathrm{~kg} / \mathrm{m}^{2}\right)$, normal weight $\left(18.5-24.9 \mathrm{~kg} / \mathrm{m}^{2}\right)$, overweight $\left(25.0-29.9 \mathrm{~kg} / \mathrm{m}^{2}\right)$, and obese $(\geq$ $30 \mathrm{~kg} / \mathrm{m}^{2}$ 
Table 2

Alcohol consumption and prevalence of self-reported and measured chronic diseases by characteristics among the population aged 18 years and above in India, 2007-08

\begin{tabular}{|c|c|c|c|}
\hline \multirow[b]{2}{*}{ Socio-demographic characteristics } & \multirow{2}{*}{$\begin{array}{c}\text { Alcohol } \\
\text { consumption }\end{array}$} & \multicolumn{2}{|c|}{ Prevalence of diseases } \\
\hline & & $\begin{array}{c}\text { Self-reported chronic } \\
\text { diseases }\end{array}$ & $\begin{array}{c}\text { Measured } \\
\text { chronic diseases }\end{array}$ \\
\hline Number of sample & 1,432 & 1,967 & 4,091 \\
\hline Overall & 17.0 & 18.0 & 37.5 \\
\hline \multicolumn{4}{|l|}{ Place of residence } \\
\hline Urban & 13.5 & 20.0 & 37.4 \\
\hline Rural & 18.5 & 17.1 & 37.5 \\
\hline \multicolumn{4}{|l|}{ Sex } \\
\hline Male & 31.4 & 17.8 & 33.7 \\
\hline Female & 1.5 & 18.3 & 41.5 \\
\hline \multicolumn{4}{|l|}{ Age group } \\
\hline $18-39$ & 14.7 & 10.4 & 26.2 \\
\hline $40-59$ & 20.7 & 22.8 & 44.6 \\
\hline 60 and above & 15.1 & 33.3 & 59.8 \\
\hline \multicolumn{4}{|l|}{ Highest education level } \\
\hline No education & 15.0 & 18.6 & 43.6 \\
\hline$\leq$ Primary & 19.5 & 17.4 & 40.2 \\
\hline Secondary & 18.8 & 17.0 & 32.5 \\
\hline High school and above & 15.9 & 18.5 & 29.3 \\
\hline \multicolumn{4}{|l|}{ Wealth Quintile } \\
\hline Poorest & 19.2 & 14.8 & 37.1 \\
\hline Poor & 18.8 & 15.2 & 37.9 \\
\hline Middle & 17.5 & 18.8 & 39.6 \\
\hline Rich & 14.0 & 20.0 & 38.8 \\
\hline Richest & 15.4 & 21.4 & 34.2 \\
\hline \multicolumn{4}{|l|}{ Religion } \\
\hline Hindu & 18.5 & 18.1 & 37.3 \\
\hline Others $^{+}$ & 8.9 & 17.5 & 38.7 \\
\hline \multicolumn{4}{|l|}{ Caste group } \\
\hline Scheduled Caste (SC)/Scheduled Tribes (ST) & 26.4 & 14.7 & 36.8 \\
\hline Other than ST/SC & 13.9 & 19.1 & 37.7 \\
\hline \multicolumn{4}{|l|}{ Physical activity } \\
\hline Non-active & 9.5 & 23.7 & 42.9 \\
\hline Moderate active & 14.3 & 21.4 & 38.5 \\
\hline Vigorously active & 20.2 & 14.5 & 36.0 \\
\hline \multicolumn{4}{|l|}{ Nutrition } \\
\hline Less than 5 servings of fruits and vegetables/day & 16.8 & 18.0 & 37.7 \\
\hline$\geq 5$ servings of fruits and vegetables/day & 21.1 & 18.5 & 34.6 \\
\hline \multicolumn{4}{|l|}{ Any tobacco use } \\
\hline No & 4.0 & 16.7 & 35.6 \\
\hline Yes & 33.2 & 19.7 & 39.8 \\
\hline \multicolumn{4}{|l|}{ Body Mass Index^^ } \\
\hline Underweight & 18.0 & 17.0 & 37.1 \\
\hline Normal weight & 17.0 & 16.3 & 35.7 \\
\hline Overweight & 14.8 & 27.4 & 46.7 \\
\hline Obese & 9.5 & 33.3 & 47.2 \\
\hline
\end{tabular}

+ Includes Islam, Buddhism, Christian, Jainism, Sikhism, and others

\# Alcohol consumption considered ever or current drinkers that drink alcohol such as beer, wine, spirits, etc.

AAny tobacco includes ever or current users of smoke or smokeless tobacco products daily such as cigarettes, cigars, pipes, chewing tobacco, or snuff

${ }^{\wedge}$ Body mass index was categorized as underweight $\left(<18.5 \mathrm{~kg} / \mathrm{m}^{2}\right)$, normal weight $\left(18.5-24.9 \mathrm{~kg} / \mathrm{m}^{2}\right)$, overweight $\left(25.0-29.9 \mathrm{~kg} / \mathrm{m}^{2}\right)$, and obese $(\geq$ $30 \mathrm{~kg} / \mathrm{m}^{2}$ )

Note: Self-reported and measured chronic diseases included hypertension, depressions, asthma, COPD, and angina

$\mathrm{N}=10,914$

Results in Table 2 indicate that alcohol consumption was higher in the rural areas $(18.5 \%)$ than in the urban areas $(13.5 \%)$. Fewer females consumed alcohol (1.5\%) compared to males $(31.4 \%)$. Alcohol consumption was highest
(20.7\%) in the 40-59 age group, and lowest (14.7\%) in the 18-39 age group. Consumption of alcohol decreased with increase in income, but it was highest among those who were vigorously active (20.2\%), used tobacco (33.2\%), had 
adequate nutrition $(21.1 \%)$, and were underweight (18.0\%). The prevalence of measured diseases was almost double $(37.5 \%)$ that of self-reported diseases (18.0\%). Both measured and self-reported chronic diseases were most prevalent among females, those aged 60 and above, and those with no education. The prevalence of both selfreported and measured chronic diseases was higher in the physically inactive population $(23.7 \%$ and $42.9 \%$, respectively) compared with the vigorously active population $(14.5 \%$ and $36.0 \%$, respectively). The prevalences of self-reported and measured chronic diseases were $19.7 \%$ and $39.8 \%$, respectively, among tobacco users. Similarly, the prevalence rates of self-reported and measured chronic disease were $33.3 \%$ and $47.2 \%$, respectively, among those with a body mass index in the obese range, and $27.4 \%$ and $46.7 \%$, respectively, among those with a body mass index in the overweight range.

The difference in the prevalence of self-reported and measured chronic diseases among drinkers is presented in Figure 1. It shows that measured symptoms of all conditions were higher than self-reported diagnoses of these conditions. For example, among drinkers the prevalence of measured angina, COPD and asthma reported were more than double self-reported estimates, while the differences in prevalence between measured and self-reported depression and hypertension were lower.

\section{Figure 1}

Prevalence of self-reported and measured chronic diseases among drinkers in population aged 18 years and above in India, 2007-08

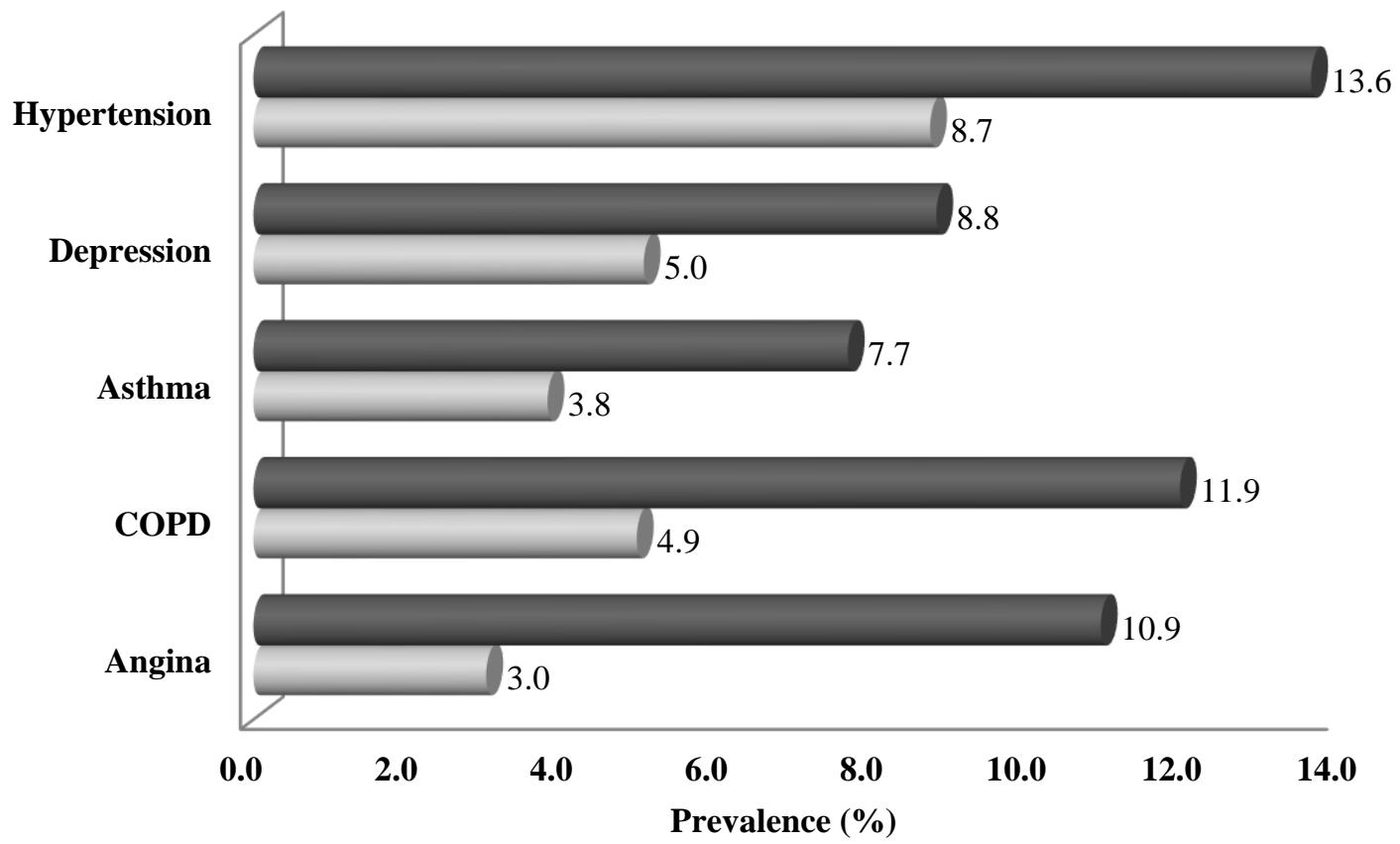

\section{- Measured chronic diseases}

Table 3 presents the adjusted odds ratios of the logistic regression model for each of the self-reported and measured chronic diseases by quantity and pattern of alcohol drinking adjusting for lifestyle and socio-demographic characteristics. The analysis was performed in three steps (adjusting for lifestyle behaviours and socio-demographic factors in all steps). In step-1, the adjusted odds ratios were estimated after adjusting for alcohol use only (excluding the pattern of alcohol consumption and quantity of alcohol consumption), in step-2 this adjustment was performed for pattern of alcohol consumption only (excluding the alcohol use and intensity of alcohol consumption), and finally in step-3 intensity of alcohol consumption was estimated (excluding the alcohol use and pattern of alcohol

\section{Self-reported chronic diseases}

consumption). Alcohol consumption was found to be associated at the $\mathrm{P}<0.1$ level with self-reported hypertension $(\mathrm{OR}=1.39 ; 95 \% \mathrm{CI}=0.94,2.06)$. Moderate drinking was found to have a significant association with self-reported hypertension $(\mathrm{OR}=1.68 ; 95 \%$ CI $=1.10,2.55)$. Consumption of three or more alcohol drinks per session was found to be significantly associated with self-reported depression $(\mathrm{OR}=2.68 ; 95 \% \mathrm{CI}=1.32,5.45)$. Consumption of alcohol was found to be significantly associated with measured chronic diseases. Drinking - whether moderate or at least two drinks per session was found to be associated with measured chronic diseases. Moderate alcohol consumption $(\mathrm{OR}=1.67 ; 95 \% \mathrm{CI}=1.17,2.24)$ and consumption of at least two drinks per session $(\mathrm{OR}=1.74$; 
Table 3

Adjusted odds ratios of self-reported and measured chronic diseases by alcohol consumption in the population aged 18 years and above in India, 2007-08

\begin{tabular}{|c|c|c|c|c|c|c|}
\hline \multirow{2}{*}{ Alcohol consumption } & \multicolumn{6}{|c|}{ Self-reported chronic diseases adjusted odds ratio $(95 \% \mathrm{CI})$} \\
\hline & Hypertension & Depression & Asthma & COPD & Angina & $\begin{array}{c}\begin{array}{c}\text { Self-reported chronic } \\
\text { diseases }\end{array} \\
\end{array}$ \\
\hline \multicolumn{7}{|l|}{ Alcohol use $\left(\mathrm{No}^{@}\right)$} \\
\hline Yes & $1.39 *[0.94,2.06]$ & $1.42[0.87,2.31]$ & $0.95[0.58,1.55]$ & $1.39[0.75,2.57]$ & $0.79[0.42,1.49]$ & $1.29 *[0.96,1.73]$ \\
\hline \multicolumn{7}{|c|}{ Pattern of alcohol consumption ${ }^{\#}\left(\mathrm{No}^{\circledR}\right)$} \\
\hline Moderate drinking & $1.68 * *[1.10,2.55]$ & $1.47[0.88,2.45]$ & $0.90[0.58,1.40]$ & $1.54[0.81,2.93]$ & $0.81[0.43,1.53]$ & $1.41 * *[1.02,1.94]$ \\
\hline Heavy drinking & $0.66[0.29,1.49]$ & $1.26[0.54,2.96]$ & $0.49 * *[0.25,0.97]$ & $1.01[0.36,2.83]$ & $0.74[0.24,2.32]$ & $0.97[0.59,1.58]$ \\
\hline \multicolumn{7}{|c|}{ Quantity of alcohol consumption ${ }^{\# \prime \prime}\left(\mathrm{No}^{\circledR}\right)$} \\
\hline At least 2 drinks & $1.41[0.93,2.15]$ & $1.07[0.62,1.86]$ & $0.80[0.47,1.37]$ & $1.69[0.89,3.20]$ & $0.89[0.47,1.71]$ & $1.23[0.89,1.71]$ \\
\hline$\geq 3$ drinks & $1.32[0.59,2.98]$ & $2.68 * * *[1.32,5.45]$ & $1.52[0.65,3.58]$ & $0.37 * *[0.16,0.82]$ & $0.44[0.13,1.49]$ & $1.47[0.90,2.39]$ \\
\hline \multirow{2}{*}{ Alcohol consumption } & \multicolumn{6}{|c|}{ Measured chronic diseases adjusted odds ratio (95\% CI) } \\
\hline & Hypertension & Depression & Asthma & COPD & Angina & $\begin{array}{c}\text { Measured chronic } \\
\text { diseases }\end{array}$ \\
\hline \multicolumn{7}{|l|}{ Alcohol use $\left(\mathrm{No}^{\Theta}\right)$} \\
\hline \multirow{2}{*}{\multicolumn{7}{|c|}{ Pattern of alcohol consumption ${ }^{\#}\left(\mathrm{No}^{\circledR}\right)$}} \\
\hline & & & & & & \\
\hline Moderate drinking & $1.67 * * *[1.16,2.42]$ & $0.90[0.58,1.40]$ & $0.90[0.58,1.40]$ & $1.33[0.89,1.98]$ & $0.81[0.43,1.53]$ & $1.48 * * *[1.12,1.95]$ \\
\hline \multirow{2}{*}{\multicolumn{7}{|c|}{ Quantity of alcohol consumption ${ }^{\# \#}\left(\mathrm{No}^{\circledR}\right)$}} \\
\hline & & & & & & \\
\hline At least 2 drinks & $1.74 * * *[1.22,2.47]$ & $0.94[0.62,1.43]$ & $1.08[0.71,1.63]$ & $1.41 *[0.96,2.06]$ & $1.36[0.90,2.06]$ & $1.57 * * *[1.20,2.06]$ \\
\hline$\geq 3$ drinks & $1.23[0.63,2.39]$ & $0.28 * * *[0.14,0.56]$ & $0.66[0.34,1.30]$ & $1.23[0.64,2.37]$ & $1.11[0.51,2.43]$ & $1.07[0.67,1.71]$ \\
\hline
\end{tabular}

" Pattern of alcohol consumption was categorized as no drinking, moderate drinking (1-3 days or fewer per month), and heavy drinking (1-4 and more days per week)

\#\# Quantity of alcohol consumption includes number of drinks per session

${ }^{\circledR}$ Reference category, ***significant at $p<.01, * *$ significant at $p<.05$, *significant at $p<.10$

Note: The regression model was run separately for each self-reported and measured chronic disease with alcohol consumption, and then with pattern and intensity of alcohol drinking.

The presented odds ratios were adjusted for lifestyle behaviors (physical activity, nutrition, tobacco use, and BMI) and socio-demographic characteristics (residence, sex, religion, caste, age, wealth index, and education)

$\mathrm{N}=10,914$ 
Table 4

The relative risk of different patterns and quantities of alcohol consumption among respondents with self-reported chronic diseases by socio-demographic characteristics in India, 2007-08

\begin{tabular}{|c|c|c|c|c|}
\hline \multirow{2}{*}{ Socio-demographic characteristics } & Moderate drinking & Heavy drinking & At least 2 drinks & $\geq 3$ drinks \\
\hline & RRR (95\% CIs) & RRR (95\% CIs) & RRR (95\% CIs) & RRR (95\% CIs) \\
\hline \multicolumn{5}{|l|}{ Base outcome: Non-drinkers } \\
\hline Moderately active & $0.53 * * *[0.36,0.80]$ & $0.89[0.41,1.93]$ & $0.56 * * *[0.38,0.84]$ & $0.86[0.34,2.17]$ \\
\hline Vigorously active & $0.59 * *[0.38,0.92]$ & $1.23[0.56,2.70]$ & $0.56 * * *[0.36,0.86]$ & $1.88[0.75,4.72]$ \\
\hline \multicolumn{5}{|l|}{ Nutrition (Less than 5 servings of fruits and vegetables/day ${ }^{\circledR}$ ) } \\
\hline$\geq 5$ servings of fruits and vegetables/day & $0.90[0.54,1.48]$ & $1.21[0.58,2.53]$ & $1.03[0.65,1.66]$ & $0.68[0.26,1.82]$ \\
\hline \multicolumn{5}{|l|}{ Any tobacco use ${ }^{\wedge}\left(\mathrm{No}^{\circledR}\right)$} \\
\hline Yes & $5.34 * * *[3.62,7.87]$ & $7.20 * * *[3.56,14.58]$ & $5.56 * * *[3.80,8.13]$ & $6.43 * * *[3.04,13.62]$ \\
\hline \multicolumn{5}{|l|}{ Body mass index ${ }^{\wedge}\left(\right.$ Normal weight $\left.^{\circledR}\right)$} \\
\hline Underweight & $0.81[0.58,1.12]$ & $1.16[0.69,1.94]$ & $0.90[0.65,1.23]$ & $0.79[0.45,1.38]$ \\
\hline Overweight & $1.23[0.77,1.96]$ & $2.29 * *[1.17,4.47]$ & $1.41[0.90,2.21]$ & $1.54[0.72,3.30]$ \\
\hline \multirow{2}{*}{\multicolumn{5}{|c|}{ Place of residence (Urban ${ }^{\circledR}$ ) }} \\
\hline & & & & \\
\hline Rural & $1.00[0.70,1.41]$ & $1.20[0.68,2.12]$ & $1.01[0.72,1.41]$ & $1.17[0.63,2.19]$ \\
\hline \multicolumn{5}{|l|}{ Sex $\left(\right.$ Male $\left.^{\circledR}\right)$} \\
\hline \multirow{2}{*}{\multicolumn{5}{|c|}{ Age group $\left(18-39^{\circledR}\right)$}} \\
\hline & & & & \\
\hline $40-59$ & $0.62 *[0.36,1.08]$ & $1.05[0.43,2.57]$ & $0.78[0.45,1.36]$ & $0.50 *[0.22,1.14]$ \\
\hline 60 and above & $0.41 * * *[0.24,0.73]$ & $0.55[0.22,1.40]$ & $0.48 * *[0.27,0.86]$ & $0.32 * * *[0.13,0.77]$ \\
\hline \multicolumn{5}{|l|}{ Highest education level (No education ${ }^{\circledR}$ ) } \\
\hline$\leq$ Primary & $1.18[0.82,1.70]$ & $0.86[0.48,1.55]$ & $1.16[0.81,1.65]$ & $0.86[0.44,1.68]$ \\
\hline Secondary & $0.82[0.50,1.32]$ & $1.14[0.57,2.28]$ & $0.81[0.51,1.30]$ & $1.18[0.55,2.53]$ \\
\hline High school \& above & $0.83[0.51,1.36]$ & $0.93[0.44,1.97]$ & $0.79[0.49,1.29]$ & $1.07[0.48,2.41]$ \\
\hline \multicolumn{5}{|l|}{ Wealth Quintile (Poorest ${ }^{\circledR}$ ) } \\
\hline Poor & $1.05[0.63,1.77]$ & $0.44 * *[0.20,0.99]$ & $0.93[0.57,1.53]$ & $0.56[0.22,1.41]$ \\
\hline Middle & $1.18[0.71,1.97]$ & $0.86[0.43,1.75]$ & $1.10[0.68,1.80]$ & $0.95[0.42,2.16]$ \\
\hline Rich & $1.24[0.75,2.06]$ & $0.80[0.39,1.62]$ & $1.08[0.67,1.77]$ & $1.13[0.51,2.51]$ \\
\hline Richest & $1.37[0.79,2.38]$ & $0.73[0.33,1.65]$ & $1.19[0.70,2.02]$ & $1.07[0.43,2.67]$ \\
\hline \multicolumn{5}{|l|}{ Religion (Hindu ${ }^{\circledR}$ ) } \\
\hline \multirow{2}{*}{\multicolumn{5}{|c|}{$\begin{array}{l}\text { Other } \\
\text { Caste group (Scheduled Caste }(\mathrm{SC}) / \text { Scheduled Tribes }(\mathrm{ST})^{\circledR} \text { ) }\end{array}$}} \\
\hline & & & & \\
\hline Other than ST/SC & $0.41 * * *[0.29,0.57]$ & $0.41 * * *[0.25,0.68]$ & $0.43 * * *[0.31,0.59]$ & $0.34 * * *[0.20,0.59]$ \\
\hline
\end{tabular}

${ }^{+}$Includes Islam, Buddhism, Christian, Jainism, Sikhism, and others

Reference category, ***significant at $\mathrm{p}<0.01, * *$ significant at $\mathrm{p}<0.05$, *significant at $\mathrm{p}<0.10$

\# Alcohol consumption pattern was categorized as no -drinking, moderate drinking (1-3 days or fewer per month), and heavy drinking (1-4 and more days per week)

\# Quantity of alcohol consumption includes number of drinks per session.

AAny tobacco use includes ever or current users of smoke or smokeless tobacco products daily such as cigarettes, cigars, pipes, chewing tobacco or snuff.

${ }^{\wedge}$ Body mass index was categorized as underweight $\left(<18.5 \mathrm{~kg} / \mathrm{m}^{2}\right)$, normal weight $\left(18.5-24.9 \mathrm{~kg} / \mathrm{m}^{2}\right)$, overweight $\left(25.0-29.9 \mathrm{~kg} / \mathrm{m}^{2}\right)$, and obese $\left(\geq 30 \mathrm{~kg} / \mathrm{m}^{2}\right)$

RRR, relative risk ratio and $95 \%$ confidence intervals

All variables in the model are simultaneously adjusted for lifestyle behaviours (physical activity, nutrition, any tobacco use, body mass index) and socio-demographic characteristics (place of residence, sex, age-group, highest education level, wealth quintile, religion and caste group).

$\mathrm{N}=1967$ 
95\% CI $=1.22,2.47$ ) were associated with measured hypertension. Having at least two drinks of alcohol per session had an association with measured COPD $(\mathrm{OR}=1.41$; $95 \% \mathrm{CI}=0.96,2.06)$.

Table 4 shows that drinking behaviors among the selfreported chronic diseased population were associated with other lifestyle behaviors, adjusting for all other variables simultaneously entered into the model. Use of tobacco products among persons with chronic diseases was found to be associated with moderate drinking $(\mathrm{RRR}=5.34 ; 95 \% \mathrm{CI}$ $=3.62,7.87)$ and heavy drinking $(\mathrm{RRR}=7.20 ; 95 \% \mathrm{CI}=$ $3.56,14.58$ ) compared to non-drinkers. A similar pattern was observed with regard to the quantity of alcohol consumed. Among the group who self-reported chronic diseases respondents with a higher risk of a body mass index in the overweight range $(\mathrm{RRR}=2.29 ; 95 \% \mathrm{CI}=1.17,4.47)$ and in the obese range $(\mathrm{RRR}=2.49 ; 95 \% \mathrm{CI}=0.87,4.47)$ were more likely to be heavy drinkers.

Table 5 shows that persons who were vigorously active were more likely to consume three or more alcoholic drinks per session $(\mathrm{RRR}=3.57 ; 95 \% \mathrm{CI}=1.25,10.23)$. Tobacco smoking was associated with both pattern and quantity of alcohol consumption. Moderate alcohol drinking was significantly associated with the risk of a body mass index in the overweight range among the measured diseased population. Having three or more drinks per session was associated with a body mass index in the overweight range $(\mathrm{RRR}=1.82 ; 95 \% \mathrm{CI}=0.93,3.58)$. Females were significantly less likely to consume alcohol than males. Among the respondents with measured chronic disease, the richest group was more likely to consume a moderate amount of alcohol $(\mathrm{RRR}=1.61 ; 95 \% \mathrm{CI}=1.10,2.37)$ or at least two drinks per session $(\mathrm{RRR}=1.65 ; 95 \% \mathrm{CI}=1.14$, 2.40) than the poorest.

\section{Discussion}

The present study assessed the association of the quantity and pattern of alcohol consumption with self-reported and symptomatically measured chronic diseases, and identified the lifestyle and socio-demographic predictors of drinking among those diagnosed with these chronic diseases.The study findings show that moderate alcohol consumption has a significant association with self-reported and measured hypertension. Alcohol consumption of three or more drinks per session has a positive association with self-reported depression. Previous research has also highlighted that alcohol consumption was associated with hypertension (Roerecke et al., 2017). Research has shown that the volume of alcohol consumed is directly associated with systolic blood pressure in a linear dependent manner (increasing alcohol consumption by $10 \mathrm{~g} /$ day increased average systolic blood pressure by $1 \mathrm{mmHg}$ ) (Fan, Li, Elam-Evans, \& Balluz, 2013). High cholesterol and hypertension are associated with occasional and regular heavy drinking (Wakabayashi et al., 2015). The levels of high-density lipoprotein cholesterol and fasting blood sugar are higher among alcohol users compared to lifetime abstainers. Measured COPD has been found to have a significant association with the consumption of at least two alcoholic drinks per session (Roy et al., 2010) and our study also found evidence for this association at the $\mathrm{P}<0.1$ level.

Our study findings also indicate that alcohol consumption is significantly associated with tobacco smoking. The prevalence of self-reported and measured chronic diseases is also higher among those who both consume alcohol and smoke tobacco. A study found that the co-occurrence of alcohol consumption with tobacco smoking increased prehypertension, hypertension, and head and neck cancers, with alcohol acting as a solvent for the carcinogens that are found in tobacco smoke (Dal Maso et al., 2016; Venkataraman et al., 2013). Occasional (1-3 days/month) and frequent binge drinkers ( 9 or more days/month) were found to smoke more cigarettes per day. Frequent binge drinkers reportedly feel tempted to smoke even in a positive affective/social situation (Gubner, Delucchi, \& Ramo, 2016). Only intermediate binge drinkers (4-8 days/month) make a serious attempt to quit tobacco (Gubner et al., 2016). According to a study done in India, about one-third of tobacco users (30\%) (aged 15-49) attempt to quit tobacco (Pradhan \& Patel, 2019). The Pradhan and Patel study also suggests that along with quitting tobacco, quitting alcohol is important to help prevent chronic diseases and related morbidity.

Our study findings show that the prevalence of self-reported and measured chronic diseases is lower among the vigorously active population. Alcohol consumption is higher among the more active group. Body mass index measures in the overweight and obese range have a significant and close to significant association with heavy alcohol drinking in the self-reported chronic diseased population. A micro-level study in Bihar found that alcohol consumption led to weight gain, including body mass index measures in the overweight range, which is one of the risks factors for morbidities and chronic diseases (Ghosh, Sarkar, Pal, \& Mukherjee, 2015). Recreational alcohol drinking may lead to weight gain if physical activity does not compensate for it (Traversy \& Chaput, 2015). Regular physical activity helps in weight loss and reduces body fat, which ultimately contributes to controlling blood pressure and blood glucose (Ranasinghe, Ranasinghe, Jayawardena, \& Misra, 2013). Physical activity has been found to be a primary prevention tool against hypertension, stroke, depression, anxiety, and metabolic syndrome (Booth, Roberts, \& Laye, 2012).

The present study also revealed that some self-reported and measured chronic diseases are higher in females in India, even though they consume less alcohol compared to males. Several studies have found that alcohol drinking may not be socially acceptable for females due to socio-cultural or religious norms (Moinuddin, Goel, Saini, Bajpai \& Misra, 2016; Kumar et al., 2018). Many females cannot access liquor freely in a bar or at a wine shop. The joint-family norms prohibit consumption of alcohol at home (Moinuddin et al., 2016). The risk of chronic diseases also varies based on type of alcoholic beverage (Sesso, Cook, Buring, Manson, \& Gaziano, 2008). Another study suggests that females consume less alcohol, and that those who consume it use home-brewed or country liquor (Kumar et al., 2018). 
Table 5

The relative risk of different patterns and intensity of alcohol consumption among respondents with measured chronic diseases by socio-demographic characteristics in India, 2007-08

\begin{tabular}{|c|c|c|c|c|}
\hline \multirow{2}{*}{ Socio-demographic characteristics } & Moderate drinkers & Heavy drinkers & At least 2 drinks & $\geq 3$ drinks \\
\hline & RRR (95\% CIs) & RRR (95\% CIs) & RRR (95\% CIs) & RRR (95\% CIs) \\
\hline \multicolumn{5}{|l|}{ Base outcome: Non-drinkers } \\
\hline \multicolumn{5}{|l|}{ Physical activity (Non-active ${ }^{\circledR}$ ) } \\
\hline Moderately active & $0.71 * *[0.51,1.00]$ & $1.13[0.58,2.22]$ & $0.72 *[0.52,1.01]$ & $1.54[0.53,4.45]$ \\
\hline Vigorously active & $0.78[0.55,1.11]$ & $1.70[0.86,3.36]$ & $0.77[0.55,1.09]$ & $3.57 * *[1.25,10.23]$ \\
\hline \multicolumn{5}{|c|}{ Nutrition (Less than 5 servings of fruits and vegetables/day ${ }^{\circledR}$ ) } \\
\hline \multirow{2}{*}{\multicolumn{5}{|c|}{ Any tobacco use $\left(\mathrm{No}^{\circledR}\right)$}} \\
\hline & & & & \\
\hline Yes & $5.49 * * *[4.08,7.37]$ & $8.25 * * *[4.77,14.27]$ & $6.30 * * *[4.72,8.42]$ & $4.76 * * *[2.59,8.72]$ \\
\hline \multicolumn{5}{|l|}{ Body mass index (Normal weight ${ }^{\circledR}$ ) } \\
\hline Underweight & $0.92[0.73,1.16]$ & $0.96[0.67,1.38]$ & $0.96[0.77,1.20]$ & $0.78[0.50,1.24]$ \\
\hline Overweight & $1.36 *[0.95,1.95]$ & $1.26[0.70,2.25]$ & $1.26[0.88,1.79]$ & $1.82 *[0.93,3.58]$ \\
\hline Obese & $0.56[0.24,1.32]$ & $1.77[0.73,4.28]$ & $0.87[0.43,1.75]$ & $0.78[0.17,3.49]$ \\
\hline \multicolumn{5}{|l|}{ Place of residence (Urban ${ }^{\circledR}$ ) } \\
\hline Rural & $1.09[0.83,1.43]$ & $1.36[0.86,2.13]$ & $1.10[0.85,1.43]$ & $1.53[0.84,2.79]$ \\
\hline \multicolumn{5}{|l|}{ Sex $\left(\right.$ Male $\left.^{\circledR}\right)$} \\
\hline Female & $0.10 * * *[0.05,0.21]$ & $0.11 * * *[0.07,0.18]$ & $0.09 * * *[0.07,0.12]$ & $0.06 * * *[0.03,0.13]$ \\
\hline \multicolumn{5}{|l|}{ Age group (18-39 $\left.{ }^{\circledR}\right)$} \\
\hline $40-59$ & $0.94[0.64,1.38]$ & $1.70 *[0.94,3.07]$ & $1.18[0.82,1.72]$ & $0.83[0.44,1.58]$ \\
\hline 60 and above & $0.70 *[0.47,1.04]$ & $0.88[0.46,1.67]$ & $0.76[0.52,1.13]$ & $0.76[0.38,1.52]$ \\
\hline \multicolumn{5}{|l|}{ Highest education level (No education ${ }^{\circledR}$ ) } \\
\hline$\leq$ Primary & $1.02[0.79,1.33]$ & $1.17[0.78,1.76]$ & $1.05[0.82,1.35]$ & $1.11[0.68,1.83]$ \\
\hline Some secondary & $0.77[0.54,1.12]$ & $1.4[0.82,2.38]$ & $0.90[0.64,1.27]$ & $0.89[0.43,1.85]$ \\
\hline Completed high school \& above & $0.65 * *[0.45,0.94]$ & $0.98[0.55,1.75]$ & $0.68 * *[0.47,0.97]$ & $1.01[0.50,2.04]$ \\
\hline \multicolumn{5}{|l|}{ Wealth Quintile (Poorest ${ }^{\circledR}$ ) } \\
\hline Poor & $1.07[0.76,1.50]$ & $0.83[0.50,1.36]$ & $1.10[0.79,1.52]$ & $0.66[0.36,1.19]$ \\
\hline Middle & $1.01[0.71,1.43]$ & $0.71[0.42,1.19]$ & $1.03[0.74,1.44]$ & $0.52 * *[0.27,0.98]$ \\
\hline Rich & $0.94[0.65,1.34]$ & $0.76[0.45,1.29]$ & $0.99[0.70,1.40]$ & $0.51 * *[0.26,0.98]$ \\
\hline \multirow{2}{*}{\multicolumn{5}{|c|}{ Religion (Hindu ${ }^{\circledR}$ ) }} \\
\hline & & & & \\
\hline Others $^{+}$ & $0.42 * * *[0.30,0.59]$ & $0.42 * * *[0.24,0.73]$ & $0.39 * * *[0.28,0.54]$ & $0.59[0.31,1.12]$ \\
\hline \multicolumn{5}{|c|}{ Caste group (Scheduled Caste $(\mathrm{SC}) / \mathbf{S c h}$ cduled Tribes (ST) ${ }^{\circledR}$ ) } \\
\hline Other than ST/SC & $0.41 * * *[0.25,0.68]$ & $0.23 * * *[0.16,0.33]$ & $0.37 * * *[0.29,0.47]$ & $0.21 * * *[0.13,0.32]$ \\
\hline
\end{tabular}

${ }^{+}$Includes Islam, Buddhism, Christian, Jainism, Sikhism, Judaism and others

${ }^{\oplus}$ Reference category, ***significant at $p<.01$, **significant at $p<.05$, *significant at $p<.10$

\# Alcohol consumption pattern was categorized as: non-drinker, moderate drinker (1-3 days or less per month), and heavy drinker (1-4 and more days per week).

Quantity of alcohol consumption includes number of drinks per session

Any tobacco use includes ever or current users of smoke or smokeless tobacco products daily such as cigarettes, cigars, pipes, chewing tobacco, or snuff

${ }^{\wedge}$ Body mass index was categorized as underweight $\left(<18.5 \mathrm{~kg} / \mathrm{m}^{2}\right)$, normal weight $\left(18.5-24.9 \mathrm{~kg} / \mathrm{m}^{2}\right)$, overweight $\left(25.0-29.9 \mathrm{~kg} / \mathrm{m}^{2}\right)$, and obese $\left(\geq 30 \mathrm{~kg} / \mathrm{m}^{2}\right)$

$\mathrm{N}=4,091$ 
Furthermore, another study has shown that drinking among women was earlier a taboo, but now women are often drinking at social gatherings (Arora et al., 2017). Several other behavioral and metabolic risk factors may cause chronic diseases among women. Future studies are required to assess gender differentials in the association of alcohol consumption with chronic diseases adjusting for sociodemographic gradients.

A key limitation of this study is that it included crosssectional data, meaning assessment of the causal relationship of alcohol with chronic diseases was not possible. SAGE is a longitudinal study, but Wave 2 data are not available in the public domain. A second limitation of the data is that the measured information on asthma, angina and depression was based on the self-reporting of symptoms, which may have been prone to reporting bias, particularly among women, who have been shown to express health related concerns more frequently than men. Further, the study also observed that the prevalence of measured chronic diseases is double then prevalence of self-reported diseases, which indicates that a higher proportion of the population suffers from chronic diseases but remains un-diagnosed (Arokiasamy et al., 2017). The intensity and patterns of alcohol drinking were estimated for a 12-month period, and may have been prone to recall bias. The study also provides information on physical activity of at least 10 minutes during the preceding seven days, but the survey did not enquire whether physical activity was performed before or after having contracted the chronic disease. Furthermore, there is also no information available in the data about whether the participant quit alcohol consumption before or after the onset of chronic disease. The present study did not assess the strength or quality of alcoholic beverage consumed, which may also be a predictor of chronic diseases.

Females drink less but appear to have a higher risk of chronic diseases as measured in these surveys. There is a major difference in drinking by males versus females and different risk factors may be associated with women's health and chronic diseases than men's. Future studies should analyse the data for men and women separately.

In conclusion, the study findings demonstrate that alcohol is associated with certain key chronic diseases. Moderate alcohol drinking was significantly associated with selfreported and measured hypertension. Consumption of three or more drinks per session of alcohol consumption was associated with self-reported depression. A future longitudinal study is required to investigate in more detail relationships between alcohol and chronic diseases by gender. The study suggests that there is an urgent need for a targeted multisectoral approach to focus on awareness and reduction of risk factors for chronic diseases in India, including the effect of even moderate drinking on chronic health.

\section{References}

Ahangari, A., Stewart Williams, J., \& Myleus, A. (2016). Pain and alcohol consumption among older adults: Findings from the World Health Organization Study on Global AGEing and Adult Health, Wave 1. Tropical Medicine and International Health, 21(10), 12821292. doi: $10.1111 / \mathrm{tmi} .12757$

Arokiasamy, P., Parasuraman, S., Sekher, T. V., \& Lhungdim, H. (2013). Study on Global AGEing and Adult Health (SAGE) Wave 1, India National Report. International Institute for Population Sciences. Geneva: World Health Organization.

Arokiasamy, P., Uttamacharya, Kowal, P., Capistrant, B. D., Gildner, T. E., Thiele, E., . . . Chatterji, S. (2017). Chronic noncommunicable diseases in 6 low- and middle-income countries: Findings from Wave 1 of the World Health Organization's Study on Global AGEing and Adult Health (SAGE). American Journal of Epidemiology, 185(6), 414-428. doi:10.1093/aje/kww125

Arora, M., Tewari, A., Bassi, S., Chauhan, K., Bhasin, S., Bakshi, A., \& Andréasson, A. (2017). Exploring perceptions of alcohol use in two Indian states: A qualitative study from Delhi and Haryana, India. The International Journal of Alcohol and Drug Research, 6(1), 1-6. doi:http://dx.doi.org/10.7895/ijadr.v6i1.238

Bhamra, A., Shanker, H., \& Niazi, Z. (2015). Achieving the Sustainable Development Goals in India. A Study of Financial Requirements and Gaps. Technology and Action for Rural Advancement, A Social Enterprise of Development Alternatives Group. New Dehli, India: Devalt.

Bhise, M. D., \& Patra, S. (2018). Prevalence and correlates of hypertension in Maharashtra, India: A multilevel analysis. PLOS One, 13(2), e0191948. doi:10.1371/journal.pone.0191948

Booth, F. W., Roberts, C. K., \& Laye, M. J. (2012). Lack of exercise is a major cause of chronic diseases. Comprehensive Physiology, 2(2), 1143-1211. doi: $10.1002 / \mathrm{cphy} . \mathrm{c} 110025$

Dal Maso, L., Torelli, N., Biancotto, E., Di Maso, M., Gini, A., Franchin, G., . . . Polesel, J. (2016). Combined effect of tobacco smoking and alcohol drinking in the risk of head and neck cancers: A re-analysis of casecontrol studies using bi-dimensional spline models. European Journal of Epidemiology, 31(4), 385-393. doi:10.1007/s 10654-015-0028-3

Dandona, L., Dandona, R., Kumar, G. A., Sukla, D. K., Paul, V. K., Balakrishnan, K., . . Swaminathan, S. (2017). Nations within a nation: Variations in epidemiological transition across the states of India, 1990-2016 in the Global Burden of Disease Study. Lancet,390(10111), 2437-2460. doi:10.1016/s0140-6736(17)32804-0

Fan, A. Z., Li, Y., Elam-Evans, L. D., \& Balluz, L. (2013). Drinking pattern and blood pressure among nonhypertensive current drinkers: Findings from 19992004 National Health and Nutrition Examination Survey. Clinical Epidemiology, 5, 21-27. doi:10.2147/clep.s12152 
Fishbacher, C. M., Bhopal, R., N., Unwin, N., White, M., \& Alberti, K. G. (2001). The performance of the Rose Angina Questionare in South Asian and European origin populations: A comparative study in Newcastle, UK. International Journal of Epidemiology, 30(5), 1009-1016.

Ghosh, A., Sarkar, D., Pal, R., \& Mukherjee, B. (2015). Correlates of overweight and obesity among urban adolescents in Bihar, India. Journal of Family Medicine and Primary Care, 4(1), 84-88. doi:10.4103/22494863.152261

Gubner, N. R., Delucchi, K. L., \& Ramo, D. E. (2016). Associations between binge drinking frequency and tobacco use among young adults. Addictive Behaviors, 60, 191-196. doi:10.1016/j.addbeh.2016.04.019

Gutjahr, E., Gmel, G., \& Rehm, J. (2001). Relation between average alcohol consumption and disease: An overview. European Addiction Research, 7(3), 117127. doi: $10.1159 / 000050729$

Hoth, K. F., Wamboldt, F. S., Strand, M., Ford, D. W., Sandhaus, R. A., Strange, C., . . Holm, K. E. (2013). Prospective impact of illness uncertainty on outcomes in chronic lung disease. Health Psychology, 32(11), 1170-1174. doi: $10.1037 / \mathrm{a} 0032721$

Ji, A., Lou, P., Dong, Z., Xu, C., Zhang, P., Chang, G., \& Li, T. (2018). The prevalence of alcohol dependence and its association with hypertension: A population-based cross-sectional study4 in Xuzhou City, China. BMC Public Health, 18(364), 1-7. doi:10.1186/s12889-0185276-1

Kessler, R. C., \& Ustun, T. B. (2004). The World Mental Health (WMH) Survey Initiative Version of the World Health Organization (WHO) Composite International Diagnostic Interview (CIDI). International Journal of Methods in Psychiatric Research, 13(2), 93-121.

Krishnan, A., Shah, B., Lal, V., Shukla, D. K., Paul, E., \& Kapoor, S. K. (2008). Prevalence of risk factors for non-communicable disease in a rural area of Faridabad district of Haryana. Indian Journal of Public Health, 52(3), 117-124.

Kumar, K., Kumar, S., \& Singh, A. K. (2018). Prevalence and socio-demographic correlates of alcohol consumption: Survey findings from five states in India. Drug and Alcohol Dependence, 185, 381-390. doi:10.1016/j.drugalcdep.2017.12.024

Lachenmeier, D. W., \& Rehm, J. (2009). Unrecorded alcohol: A threat to public health? Addiction, 104(6), 875-877. doi:10.1111/j.1360-0443.2009.02587.x

Larsson, S. C., Wallin, A., \& Wolk, A. (2018). Alcohol consumption and risk of heart failure: Meta-analysis of 13 prospective studies. The American Journal of Clinical Nutrition, 37(4), 1247-1251. doi:10.1016/j.clnu.2017.05.007

Leong, D. P., Smyth, A., Teo, K. K., McKee, M., Rangarajan, S., Pais, P., . . Yusuf, S. (2014). Patterns of alcohol consumption and myocardial infarction risk: Observations from 52 countries in the INTERHEART case-control study. Circulation, 130(5), 390-398. doi:10.1161/circulationaha.113.007627

Lieberoth, S., Backer, V., Kyvik, K. O., Skadhauge, L. R., Tolstrup, J. S., Gronbaek, M., . . . Thomsen, S. F. (2012). Intake of alcohol and risk of adult-onset asthma.
Respiratory Medicine, 106(2), 184-188. doi:10.1016/j.rmed.2011.11.004

Mahajan, H., Choo, J., Masaki, K., Fujiyoshi, A., Guo, J., Hisamatsu, T., . . Sekikawa, A. (2018). Association of alcohol consumption and aortic calcification in healthy men aged 40-49 years for the ERA JUMP Study. Atherosclerosis, 268, 84-91. doi:10.1016/j.atherosclerosis.2017.11.017

Moinuddin, A., Goel, A., Saini, S., Bajpai, A., \& Misra, R. (2016). Alcohol consumption and gender: A critical review. Journal of Psychology \& Psychotherapy, 6(3), 2-4. doi:10.4172/2161-0487.1000267

Naghavi, M., Abajobir, A. A., Abbafati, C., Abbas, K. M., Abd-Allah, F., Abera, S. F., ... Ahmadi, A. (2017). GBD 2016 Causes of Death Collaborators. Global, regional, and national age-sex specific mortality for 264 causes of death, 1980-2016: A systematic analysis for the Global Burden of Disease Study 2016. Lancet, 390(10100), 1151-1210. doi:10.1016/s01406736(17)32152-9

Parry, C. D., Patra, J., \& Rehm, J. (2011). Alcohol consumption and non-communicable diseases: Epidemiology and policy implications. Addiction, 106(10), 1718-1724. doi:10.1111/j.13600443.2011.03605.x

Patel, S., Ram, F., Patel, S. K., \& Kumar, K. (2019). Association of behavioral risk factors with selfreported and symptom or measured chronic diseases among adult population (18-69 years) in India: Evidence from SAGE study. BMC Public Health, 19(1), 560. doi:10.1186/s12889-019-6953-4

Prabhakaran, D., Jeemon, P., Sharma, M., Roth, G. A., Johnson, C., Harikrishnan, S., . . Dandona, L. (2018). The changing patterns of cardiovascular diseases and their risk factors in the states of India: The Global Burden of Disease Study 1990-2016. The Lancet Global Health, 6(12), e1339-e1351. doi: $10.1016 / \mathrm{s} 2214-109 x(18) 30407-8$

Pradhan, M. R., \& Patel, S. K. (2019). Correlates of tobacco quit attempts and missed opportunity for tobacco cessation among the adult population in India. Addictive Behaviors, 95, 82-90. doi: 10.1016/j.addbeh.2019.03.003

Ranasinghe, C. D., Ranasinghe, P., Jayawardena, R., \& Misra, A. (2013). Physical activity patterns among South-Asian adults: A systematic review. International Journal of Behavioral Nutrition and Physical Activity, 10, 116. doi:10.1186/1479-5868-10-116

Rehm, J., Baliunas, D., Borges, G. L., Graham, K., Irving, H., Kehoe, T., . . . Taylor, B. (2010). The relation between different dimensions of alcohol consumption and burden of disease: An overview. Addiction, 105(5), 817-843. doi:10.1111/j.1360-0443.2010.02899.x

Rehm, J., Marmet, S., Anderson, P., Gual, A., Kraus, L., Nutt, D. J., . . Gmel, G. (2013). Defining substance use disorders: Do we really need more than heavy use? Alcohol and Alcoholism, 48(6), 633-640. doi:10.1093/alcalc/agt127

Ridolfo, B., \& Stevenson, C. (2001). The quantification of drug-caused mortality and morbidity in Australia, 1998. Drug Statistics Series no. 7. Australian Institute of Health and Welfare, Retrieved from: 
https://www.aihw.gov.au/getmedia/7e677c0d-e6c14ec8-a78f62982758f61f/qdcmma98.pdf.aspx?inline=true

Roerecke, M., Kaczorowski, J., Tobe, S. W., Gmel, G., Hasan, O. S. M., \& Rehm, J. (2017). The effect of a reduction in alcohol consumption on blood pressure: A systematic review and meta-analysis. Lancet Public Health, 2(2), e108-e120. doi:10.1016/s24682667(17)30003-8

Roy, A., Prabhakaran, D., Jeemon, P., Thankappan, K. R., Mohan, V., Ramakrishnan, L., . . . Reddy, K. S. (2010). Impact of alcohol on coronary heart disease in Indian men. Atherosclerosis, 210(2), 531-535. doi:10.1016/j.atherosclerosis.2010.02.033

Ruan, Y., Guo, Y., Zheng, Y., Huang, Z., Sun, S., Kowal, P., ... Wu, F. (2018). Cardiovascular disease (CVD) and associated risk factors among older adults in six lowand middle-income countries: Results from SAGE Wave 1. BMC Public Health, 18(1), 778. doi:10.1186/s12889-018-5653-9

Santana, N. M. T., Mill, J. G., Velasquez-Melendez, G., Moreira, A. D., Barreto, S. M., Viana, M. C., \& Molina, M. D. C. B. (2018). Consumption of alcohol and blood pressure: Results of the ELSA-Brasil study. PLOS One, 13(1), e0190239. doi:10.1371/journal.pone.0190239

Sesso, H. D., Cook, N. R., Buring, J. E., Manson, J. E., \& Gaziano, J. M. (2008). Alcohol consumption and the risk of hypertension in women and men. Hypertension, 51(4), 1080-1087. doi:10.1161/hypertensionaha.107.104968

Shield, K. D., Parry, C., \& Rehm, J. (2013). Chronic diseases and conditions related to alcohol use. Alcohol Research, 35(2), 155-173.

Stata Corp (2013) Stata Statistical Software: Release 13. StataCorp LP, College Station, TX

Traversy, G., \& Chaput, J. P. (2015). Alcohol consumption and obesity: An update. Current Obesity Reports, 4(1), 122-130. doi:10.1007/s13679-014-0129-4

Vellakkal, S., Subramanian, S. V., Millett, C., Basu, S., Stuckler, D., \& Ebrahim, S. (2013). Socioeconomic inequalities in non-communicable diseases prevalence in India: Disparities between self-reported diagnoses and standardized measures. PLOS One, 8(7), e68219. doi:10.1371/journal.pone.0068219

Venkataraman, R., Kumar, S. B. P., Kumaraswamy, M., Singh, R., Pandey, M., Tripathi, P., . . . Vaibhav, P. (2013). Smoking, alcohol and hypertension. International Journal of Pharmacy and Pharmaceutical Sciences, 5(4), 28-32.

Wakabayashi, M., McKetin, R., Banwell, C., Yiengprugsawan, V., Kelly, M., Seubsman, S. A., . . . Sleigh, A. (2015). Alcohol consumption patterns in Thailand and their relationship with non-communicable disease. BMC Public Health, 15, 1297. doi:10.1186/s12889-015-2662-9

World Health Organization. (2008). The Global Burden of Disease, 2004 update. Geneva, Switzerland, World Health Organization. Retrieved from: https://www.who.int/healthinfo/global_burden_disease /GBD_report_2004update_full.pdf

World Health Organization. (2013). Obesity and overweight fact sheet. Geneva, Switzerland: World Health
Organization. Retrieved from: http://www.who.int/mediacentre/factsheets/fs311/en/

World Health Organization. (2014). Global status report on noncommunicable diseases 2014 (No. WHO/NMH/NVI/15.1). World Health Organization. Retrieved from: http://apps.who.int/iris/bitstream/10665/148114/1/978 9241564854_eng.pdf?ua $=1$

World Health Organization. (2018). Global status report on alcohol and health 2018. Geneva, Switzerland: World Health Organization. Retrieved from: https://apps.who.int/iris/bitstream/handle/10665/27460 3/9789241565639-eng.pdf?ua=1

Xu, W. H., Zhang, X. L., Gao, Y. T., Xiang, Y. B., Gao, L. F., Zheng, W., \& Shu, X. O. (2007). Joint effect of cigarette smoking and alcohol consumption on mortality. Preventive Medicine, 45(4), 313-319. doi:10.1016/j.ypmed.2007.05.015 